\section{Original Article}

Ann Liver Transplant 2021;1(1):18-23 https://doi.org/10.52604/alt.21.0011

Check for updates
ALT

pISSN 2765-5121

eISSN 2765-6098

\title{
Risk factors for alcohol recidivism after liver transplantation
}

\author{
Hyeok Jun Yun ${ }^{1}$, Jae Geun Lee ${ }^{1,2}$, Hyun Jeong Kim¹, Dai Hoon Han¹, Gi Hong Choi', \\ Myoung Soo Kim ${ }^{1,2}$, Jin Sub $\mathrm{Choi}^{1,2}$, Soon II Kim ${ }^{1,2}$, Dong Jin Joo ${ }^{1,2}$ \\ ${ }^{1}$ Department of Surgery, Yonsei University College of Medicine \\ ${ }^{2}$ The Research Institute for Transplantation, Yonsei University College of Medicine, Seoul, Korea
}

Received April 24, 2021

Revised May 15, 2021

Accepted May 17, 2021

Corresponding author: Dong Jin Joo Department of Surgery, Yonsei University College of Medicine, 50-1 Yonsei-ro, Seodaemun-gu, Seoul 03722, Korea

E-mail: djjoo@yuhs.ac

https://orcid.org/0000-0001-8405-1531

(c) The Korean Liver Transplantation Society This is an Open Access article distributed under the terms of the Creative Commons Attribution Non-Commercial License (http://creativecommons.org/licenses/ by-nc/4.0/) which permits unrestricted non-commercial use, distribution, and reproduction in any medium, provided the original work is properly cited.
Background: Alcoholic liver disease (ALD) has been increasing recently and the second most common indication for liver transplantation (LT) in Korea. Even after LT, alcohol recidivism can be a problem interfering with the patients' long-term survival and graft function. This study was conducted to analyze the clinical course and preand post-transplantation risk factors for alcohol recidivism in transplant recipients with ALD.

Methods: Of 592 liver transplant recipients, sixty-two patients underwent LT for ALD between Jan 2005 and Dec 2014. We retrospectively collected and analyzed the data from our electrical medical records.

Results: Out of the 62 ALD recipients, 57 patients were male. Their mean age was $52.4 \pm 8.3$ years. The mean abstinence period of them before transplantation was $17.7 \pm 30.0$ months. Sixteen recipients $(25.8 \%)$ showed alcohol recidivism at $15.9 \pm 13.7$ months after LT. Patients who showed alcohol recidivism had a significantly longer duration of drink before transplantation than non-recidivism patients ( $35.4 \pm 6.3$ vs $30.9 \pm 9.4$ years, respectively, $p=0.038$ ). In terms of alcohol consumption, the recidivism group showed more alcohol drinking than the non-recidivism group (123.0 \pm 67.2 vs $81.6 \pm 61.0$ units, respectively, $p=0.026$ ). The abstinence period before LT was not significantly different. In the multivariate analysis, the amount of alcohol consumption before transplantation was considered to play a risk factor for alcohol recidivism after transplantation $(p=0.05)$.

Conclusion: Information about duration and consumption of alcohol drink before LT helps to predict alcohol recidivism after LT in patients with ALD, allowing early awareness and specific postoperative care.

Keywords: Alcohol; Liver transplantation; Recidivism; Survival

\section{INTRODUCTION}

Alcohol liver disease (ALD) becomes one of the most common causes of cirrhosis and liver transplantation worldwide. ALD, alone or in combination with other liv- er-related diseases such as hepatitis B or $\mathrm{C}$ viruses and $\mathrm{NASH}$, is one of the most common indications for LT in North America $(24.1 \%)$ and Europe $(23 \%)$ [1,2]. In Korea, its incidence has been increasing recently, the most common indication for deceased donor LT and the second most 
common indication for living donor LT [3]. According to a recent report, excessive alcohol consumption even after liver transplantation is 5.8- to 17.4 -fold more frequent in patients with ALD than in those with other indications for LT [4].

As the number of LT for ALD patients has been increasing, the number of patients with alcohol recidivism after LT can be increasing. In patients with ALD, alcohol recidivism is still occurring despite a lot of efforts to prevent recidivism after LT. Several approaches have been conducted to reduce alcohol recidivism in alcoholic patients after LT, such as management of alcoholic patients by addiction psychiatrists and presence of an alcohol addiction unit within a transplant center, but there is no standardized approach, and the available data are few and often controversial $[5,6]$. Although most transplant centers enforce a 6-month rule of abstinence, the alcohol recidivism rate after LT has been reported $20-50 \%[7,8]$.

Resumption of alcohol drinking can lead to non-compliance with the transplant follow-up program, which can make worse outcomes for the patients [9]. In Europe, 5- and 10-year survival rates in ALD patients after liver transplantation are $73 \%$ and $59 \%$, respectively. However, a significant drop in the survival rate in patients with recidivism was not observed $[2,10]$.

This study was conducted to analyze the clinical course, outcomes, and pre- and post-transplant risk factors for alcohol recidivism in transplant recipients with ALD.

\section{MATERIALS AND METHODS}

We retrospectively reviewed the medical records of 62 ALD patients among 592 liver recipients who underwent liver transplantation in Severance hospital between Jan 2005 and Dec 2014. Six patients who could not be followed up due to in-hospital mortality were excluded.

The diagnosis of ALD was based on a documented history of alcohol drinking experience that could lead to endstage liver disease and exclusion of non-alcoholic causes that can lead to end-stage liver disease. Patients were considered for liver transplantation based on standard listing criteria.

During the follow-up visits after LT, patients were routinely questioned about alcohol consumption and were reminded about the necessity to remain abstinent, as well as given advice on the negative effects of alcohol use. And these patients followed up with psychiatric consultation.

Alcohol recidivism was defined as any alcohol con- sumption that was noticed by the patients and/or their family members during the following periods. We evaluated the incidence of alcohol recidivism, graft function, patient survival rates, and risk factors affecting the recurrence of alcohol. Also, we evaluate the effectiveness of the 6-month abstinence rule on the prevention of alcohol recidivism. To evaluate alcohol drinking amount, we defined 1 unit of alcohol consumption as $10 \mathrm{~g} /$ week of alcohol regardless of the alcohol types that the patients drank.

Comparison analysis of liver function was performed between the alcohol recidivism group and non-recidivism group to evaluate the effects of alcohol on the transplanted liver.

Statistical analysis was performed using SPSS 25 (SPSS Inc., Chicago, IL, USA). Data were expressed as the mean \pm standard deviation for continuous variables and number (proportion) for categorical variables. Continuous variables were tested using independent Student's t-tests and Fisher's exact test for categorical variables. Graft survival rates were calculated using Kaplan-Meier method and the logrank test was used to evaluate statistical significance. A p-value less than 0.05 was considered statistically significant.

\section{RESULTS}

Of the 592 patients included in the study, 67 underwent LT for ALD and 525 for other indications. Among 67 ALD patients, one patient underwent retransplantation for primary non-function of the first graft and 6 patients were excluded due to in-hospital mortality after LT.

A total of 15 patients had type 2 diabetes mellitus and 19 patients had hypertension. Three patients had HBV infection and one patient had HCV infection combined with ALD. The mean abstinence period of those ALD patients before LT was $17.7 \pm 30.0$ months. The number of patients with Child-Turcotte-Pugh (CTP) classification A, B, and C were 7,26 , and 29 , respectively. Their mean MELD score was $19.3 \pm 9.1$. The donors were mainly primary family members including sons $(n=19)$, daughters $(n=4)$, brothers $(n=3)$, sisters $(n=3)$, a cousin, and a wife. Out of the patients, there was no retransplantation case.

Sixteen patients had alcohol recidivism and their onset time was $15.9 \pm 13.7$ months after LT. A comparison of clinical characteristics between the alcohol recidivism group and the non-recidivism group is shown in Table 1 . Their demographics and pretransplant conditions were not different. Table 2 shows the alcohol-related factors of 
the two groups. The alcohol recidivism group had a significantly longer drinking period before transplantation than the non-recidivism group ( $35.4 \pm 6.3$ vs $30.9 \pm 9.4$ years, respectively, $\mathrm{p}=0.038$ ). In terms of alcohol consumption, the recidivism group showed more alcohol drinking amount than the non-recidivism group (123.0 \pm 67.2 vs $81.6 \pm 61.0$ units, respectively, $p=0.026 ; 1$ unit $=10 \mathrm{~g} /$ week alcohol). Also, the alcohol recidivism group showed a tendency of shorter abstinence periods than the non-recidivism group ( $8.9 \pm 15.5$ vs $20.6 \pm 33.3$ months, respectively, $p=0.066)$. Of the patients with co-infection of hepatitis $B$ or $C(n=3)$, one

Table 1. Clinical profiles between the Alcoholic recidivism group and non-recidivism group

\begin{tabular}{lccc}
\hline & $\begin{array}{c}\text { Non-Recidivism } \\
(\mathrm{n}=46)\end{array}$ & $\begin{array}{c}\text { Recidivism } \\
(\mathrm{n}=16)\end{array}$ & p-value \\
\hline Age, mean \pm SD & $51.9 \pm 8.8$ & $54.4 \pm 6.7$ & 0.306 \\
\hline Sex (male\%) & $42(91.3 \%)$ & $15(93.8 \%)$ & 0.757 \\
\hline DM, $n(\%)$ & $12(26.1 \%)$ & $3(18.8 \%)$ & 0.555 \\
\hline HTN, $n(\%)$ & $12(26.1 \%)$ & $7(43.8 \%)$ & 0.187 \\
\hline HBV, $n(\%)^{*}$ & $2(4.3 \%)$ & $1(6.2 \%)$ & 0.760 \\
\hline HCV, $n(\%)^{*}$ & $0(0.0 \%)$ & $1(6.2 \%)$ & 0.087 \\
HCC, $n(\%)$ & $9(19.6 \%)$ & $2(12.5 \%)$ & 0.524 \\
\hline CTP, $n(\%)$ & & & 0.650 \\
Class A & $6(13.0 \%)$ & $1(6.2 \%)$ & \\
Class B & $18(39.1 \%)$ & $8(50.0 \%)$ & \\
Class C & $22(47.8)$ & $7(43.8 \%)$ & \\
MELD score, mean $\pm S D$ & $19.5 \pm 9.1$ & $18.4 \pm 8.8$ & 0.676 \\
\hline Type of graft & & & 0.562 \\
LDLT & $22(47.8 \%)$ & $9(56.2 \%)$ & \\
DDLT & $24(56.2 \%)$ & $7(43.8 \%)$ & \\
\hline
\end{tabular}

DM, diabetes mellitus; HTN, hypertension; HBV, viral hepatitis B; HCV viral hepatitis C; CTP, Child-Turcotte-Pugh score; MELD, model for endstage liver disease; LDLT, living donor liver transplantation; DDLT, deceased donor liver transplantation.

*Viral hepatitis combined cases: all livers were confirmed alcohol dominant hepatitis in the histology.

Table 2. Comparison of preoperative alcohol consumption of recidivism and non-recidivism groups

\begin{tabular}{lccc}
\hline & $\begin{array}{c}\text { Non-Recidi- } \\
\text { vism }(n=46)\end{array}$ & $\begin{array}{c}\text { Recidivism } \\
(n=16)\end{array}$ & p-value \\
\hline Duration of drink (year) & $30.9 \pm 9.4$ & $35.4 \pm 6.3$ & 0.038 \\
Consumption of alcohol (unit/week) & $81.6 \pm 61.0$ & $123.0 \pm 67.2$ & 0.026 \\
Duration of abstinence (month) & $20.6 \pm 33.3$ & $8.9 \pm 15.5$ & 0.066 \\
Abstinence $<3$ months & $19(41.3 \%)$ & $9(56.2 \%)$ & 0.301 \\
Abstinence $<6$ months & $24(52.2 \%)$ & $11(68.8 \%)$ & 0.249 \\
\hline
\end{tabular}

patient returned to alcohol abuse after LT.

The period of pre-transplantation abstinence was less than 3 months in 27 patients, 3 to 6 months in 6 patients, 6 to 12 months in 10 patients, and above 12 months in 17 patients. Patients who had abstinence periods for more than 6 months are $22(47.8 \%)$ in the non-recidivism group and $5(31.2 \%)$ in the recidivism group. Eight patients died during follow-up. Of the 16 alcohol recidivism cases, four (25\%) cases showed recidivism within the first 6 months after LT, 6 to 12 months in 4 (25\%) cases, 12 to 18 months in $1(6.3 \%)$ case, and seven $(43.8 \%)$ recidivism occurred in cases with more than 18 months after LT.

The alcoholic recidivism group showed deterioration of serum AST (127.6 $\pm 197.2 \mathrm{IU} / \mathrm{L})$, ALT (103.4 $\pm 150.0 \mathrm{IU} / \mathrm{L})$,

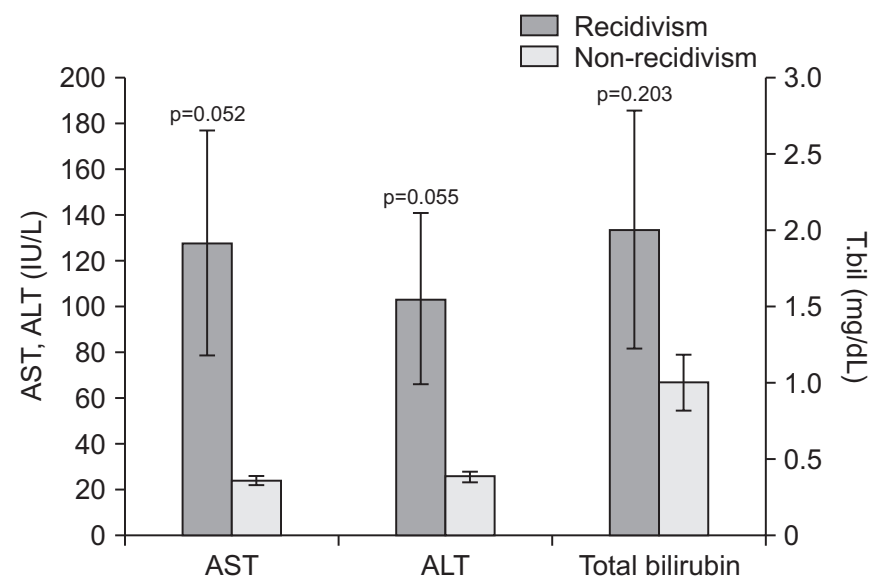

Fig. 1. Mean serum AST, ALT and Total bilirubin levels measured the time of alcohol relapse in alcohol recidivism group; compared to those of non-recidivism group at 6 months after liver transplantation.

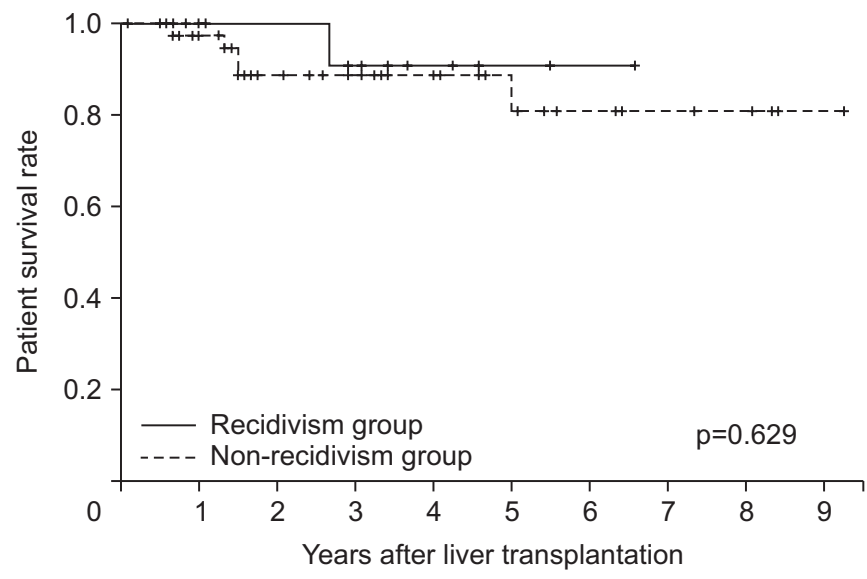

Fig. 2. Cumulative patient survival curves of alcoholic recidivism and non-recidivism groups. 
and total bilirubin levels $(2.0 \pm 3.1 \mathrm{mg} / \mathrm{dL})$ in the acute stage comparing with the non-recidivism group (Fig. 1). But these functional deteriorations became resolved after the recovery period without alcohol intake. However, in the survival analysis, there was no significant difference between the two groups (Fig. 2).

Out of the analyzed variables, consumption of alcohol was the only independently associated with the risk of alcohol recidivism in both univariate and multivariate analysis (OR=1.00, $\mathrm{Cl}=1.00-1.01, \mathrm{p}=0.05$; (Table 3). Two recipients with alcohol recidivism died because of sepsis and graft dysfunction.

\section{DISCUSSION}

ALD is a liver disease that is associated with chronic alcohol abuse. Even though there are still controversial issues, the most effective treatment for liver cirrhosis originated from ALD is liver transplantation. In the diagnosis of ALD, it is necessary to have enough consumption of alcohol and duration of drink to cause liver disease. There are no definite amount of alcohol consumption and no unified criteria for drinking duration that could induce ALD. Generally, it is known that $60-80 \mathrm{~g}$ of alcohol a day for many years may occur ALD [11]. However, this criterion is not absolute and can vary depending on various environmental and host factors.

The spectrum of ALD is wide which begins from fatty liver and proceeds alcoholic hepatitis, and alcoholic cirrhosis according to clinical and pathological findings. The primary treatment for ALD patients should start with abstinence from alcohol. As the alcoholic fatty liver stage can be mostly reversible, when patients stop drinking, it can return to normal within 4-6 weeks [12]. The survival rates of patients with alcoholic hepatitis also increase significantly when they stopped drinking. However, when alcoholic hepatitis occurs repeatedly, irreversible liver damage occurs. Alcoholic hepatitis is known to have very few clinical manifestations, ranging from mild hepatic dysfunction to severe hepatic dysfunction.

The minimum selection criteria of LT for ALD patients should require a CTP score of 7 or greater, a history of portal hypertension, or a history of spontaneous bacterial peritonitis [13]. However, the CTP score has been associated with a large number of subjective interventions and poor prognosis in the evaluation of hepatic encephalopathy and ascites. To correct this, some liver transplantation programs recommend that patients with end stage liver disease with a MELD score of 12 or more should be selected as transplant recipients $[14,15]$. However, even though the liver failure patients with ALD need $L T$, there are still many arguments including ethical issues if LT for ALD would be right or not. There would be two issues about LT for ALD. The first one is brought up by the fact that ALD patients ruin their liver by themselves. The second one would be the alcohol recidivism after LT. Alcohol recidivism can lead to damage of preciously transplanted liver and extrahepatic damage caused by alcohol itself, and lower compliance with medication and outpatient visits, resulting in graft failure.

Table 3. Multivariate analysis for prediction of alcohol recidivism

\begin{tabular}{|c|c|c|c|c|}
\hline \multirow{2}{*}{ Study characteristics } & \multicolumn{2}{|c|}{ Univariate } & \multicolumn{2}{|c|}{ Multivariate } \\
\hline & $\mathrm{OR}(95 \% \mathrm{Cl})$ & $\mathrm{p}$-value & OR $(95 \% \mathrm{Cl})$ & $\mathrm{p}$-value \\
\hline Age & $1.03(0.96-1.11)$ & 0.30 & & \\
\hline DM & $0.65(0.15-2.69)$ & 0.55 & & \\
\hline HTN & $2.20(0.67-7.22)$ & 0.19 & & \\
\hline HBV & $1.46(0.12-17.3)$ & 0.76 & & \\
\hline Type of LT (for LDLT) & $0.71(0.22-2.24)$ & 0.56 & & \\
\hline Duration of drink (year) & $1.06(0.99-1.14)$ & 0.08 & $1.06(0.98-1.14)$ & 0.11 \\
\hline Consumption of alcohol (unit/week) & $1.01(1.00-1.01)$ & 0.03 & $1.00(1.00-1.01)$ & 0.05 \\
\hline Duration of abstinence (month) & $0.98(0.95-1.01)$ & 0.20 & & \\
\hline Abstinence $<3$ months & $2.16(0.67-6.96)$ & 0.19 & & \\
\hline
\end{tabular}

DM, diabetes mellitus; HTN, hypertension; HBV, viral hepatitis B; MELD, model for end-stage liver disease; LDLT, living donor liver transplantation. 
In order to minimize alcohol recidivism, most transplant centers have studies the risk factors of recidivism including abstinence period, alcohol consumption amount, and etc (Table 4). In the literatures, the alcohol recidivism rates were reported from $11.9 \%$ to $48 \%$ [14,16-24]. Factor associated with recidivism varied according to each study such as pretransplant psychological treatment, family awareness, personality disorder, drinking duration, alcohol consumption amount, or abstinence period. Many American centers recommend to keep mandatory six-month abstinence rule before deciding LT. However, in the current study shows alcohol consumption at pre-transplant period appeared to be a more powerful risk factor to predict recidivism than the failure of 6-month abstinence period. Therefore, taking the detailed alcohol history should be done before LT to prepare their life modification after LT.

Although our center does not apply post-operative rehabilitation programs, several studies have shown significant results in reducing recidivism by applying these programs. Björnsson et al. [5]. evaluated the impact of the management of alcoholic patients by addiction psychiatrists, social workers, and tutors in the period before $\mathrm{LT}$ and reported a $22 \%$ prevalence of alcohol recidivism in the treated group vs $48 \%$ in the untreated group. The presence of an alcohol addiction unit within a liver transplant center is not usual,

Table 4. Alcohol recidivism rates and risk factors after liver transplantation reported from other studies

\begin{tabular}{|c|c|c|c|}
\hline Authors & $\begin{array}{l}\text { Patients } \\
\text { (n) }\end{array}$ & $\begin{array}{l}\text { Recidivism } \\
\text { rate }\end{array}$ & $\begin{array}{l}\text { Factors associated with } \\
\text { recidivism }\end{array}$ \\
\hline Egawa et al. [16] & 140 & $22.9 \%$ & $\begin{array}{l}\text { History of treatment for } \\
\text { psychological diseases }\end{array}$ \\
\hline Lucey et al. [17] & 59 & $34 \%$ & None \\
\hline Burra and Lucey [14] & 51 & $33 \%$ & $\begin{array}{l}\text { Patient and/or family } \\
\text { awareness of alcoholism }\end{array}$ \\
\hline Gish et al. [18] & 61 & $20 \%$ & $\begin{array}{l}\text { Personality disorder, lack } \\
\text { of compliance }\end{array}$ \\
\hline Bellamy et al. [19] & 123 & $13 \%$ & $\begin{array}{l}\text { Duration×quantity of } \\
\text { alcohol }\end{array}$ \\
\hline Tang et al. [20] & 56 & $48 \%$ & None \\
\hline Hartl et al. [21] & 120 & $16 \%$ & $\begin{array}{l}\text { Abstinence }<3 \text { months, } \\
\text { lack of compliance }\end{array}$ \\
\hline De Gottardi et al. [22] & 387 & $11.9 \%$ & $\begin{array}{l}\text { Abstinence }<6 \text { months, } \\
\text { psychiatric comorbidities, } \\
\text { HRAR }>3\end{array}$ \\
\hline Osario et al. [23] & 43 & $19 \%$ & Abstinence $<6$ months \\
\hline Pageaux et al. [24] & 53 & $32 \%$ & Abstinence $<6$ months, age \\
\hline
\end{tabular}

but the study of Addolorato et al. [6]. suggests that it could represent a useful approach to reducing alcohol recidivism after LT. Future studies will be needed to reduce recidivism by applying these rehabilitation programs as well as listening to drinking history before transplantation.

\section{CONCLUSIONS}

Information about drinking duration and consumption of alcohol at pretransplant period helps to predict alcohol recidivism after $\mathrm{LT}$ in patients with ALD, allowing early awareness and specific postoperative care.

\section{FUNDING}

This study was supported by a faculty research grant of Yonsei University College of Medicine for (6-2018-0191).

\section{CONFLICT OF INTEREST}

All authors have no conflicts of interest to declare.

\section{ORCID}

Hyeok Jun Yun Jae Geun Lee Hyun Jeong Kim Dai Hoon Han Gi Hong Choi Myoung Soo Kim Jin Sub Choi Soon II Kim Dong Jin Joo https://orcid.org/0000-0001-6004-0782 https://orcid.org/0000-0002-6722-0257 https://orcid.org/0000-0002-6033-5094 https://orcid.org/0000-0003-2787-7876 https://orcid.org/0000-0002-1593-3773 https://orcid.org/0000-0002-8975-8381 https://orcid.org/0000-0002-6467-6494 https://orcid.org/0000-0002-0783-7538 https://orcid.org/0000-0001-8405-1531

\section{AUTHORS' CONTRIBUTIONS}

Conceptualization: DJJ. Data curation: All. Formal analysis: DJJ, DHH, GHC, MSK. Funding acquisition: DJJ. Investigation: None. Methodology: DJJ. Project administration: None. Resources: DJJ, JGL. Software: None. Supervision: DJJ. Validation: None. Visualization: DJJ, HJK. Writing original draft: HJY. Writing - review \& editing: DJJ, JSC, SIK.

\section{REFERENCES}

1. Kim WR, Lake JR, Smith JM, Skeans MA, Schladt DP, Edwards EB, et al. OPTN/SRTR 2013 annual data report: liver. Am J Transplant 2015;15 Suppl 2:1-28. 
2. Adam R, Karam V, Delvart V, O'Grady J, Mirza D, Klempnauer J, et al.; All contributing centers (www.eltr.org); European Liver and Intestine Transplant Association (ELITA). Evolution of indications and results of liver transplantation in Europe. A report from the European Liver Transplant Registry (ELTR). J Hepatol 2012;57:675-688.

3. Korean Network for Organ Sharing (KONOS). Annual report of the transplant 2019 [Internet]. Seoul: KONOS 2020 [cited 2021 April 10]. Available from: https://www.konos.go.kr

4. Faure S, Herrero A, Jung B, Duny Y, Daures JP, Mura T, et al. Excessive alcohol consumption after liver transplantation impacts on long-term survival, whatever the primary indication. J Hepatol 2012;57:306-312.

5. Björnsson E, Olsson J, Rydell A, Fredriksson K, Eriksson C, Sjöberg C, et al. Long-term follow-up of patients with alcoholic liver disease after liver transplantation in Sweden: impact of structured management on recidivism. Scand J Gastroenterol 2005;40:206-216.

6. Addolorato G, Mirijello A, Leggio L, Ferrulli A, D'Angelo C, Vassallo G, et al.; Gemelli OLT Group. Liver transplantation in alcoholic patients: impact of an alcohol addiction unit within a liver transplant center. Alcohol Clin Exp Res 2013;37:16011608.

7. Lim JK, Keeffe EB. Liver transplantation for alcoholic liver disease: current concepts and length of sobriety. Liver Transpl 2004;10(10 Suppl 2):S31-S38.

8. Tome S, Lucey MR. Timing of liver transplantation in alcoholic cirrhosis. J Hepatol 2003;39:302-307.

9. Webb K, Shepherd L, Day E, Masterton G, Neuberger J. Transplantation for alcoholic liver disease: report of a consensus meeting. Liver Transpl 2006;12:301-305.

10. Burra P, Senzolo M, Adam R, Delvart V, Karam V, Germani G, et al.; ELITA; ELTR Liver Transplant Centers. Liver transplantation for alcoholic liver disease in Europe: a study from the ELTR (European Liver Transplant Registry). Am J Transplant 2010; 10:138-148.

11. Savolainen VT, Liesto K, Männikkö A, Penttilä A, Karhunen PJ. Alcohol consumption and alcoholic liver disease: evidence of a threshold level of effects of ethanol. Alcohol Clin Exp Res 1993;17:1112-1117.

12. Baptista A, Bianchu L, de Groote J, Desmet VJ, Gedigk P, Korb G, et al.; An International Group. Alcoholic liver disease: morphological manifestations. Review by an international group. Lancet 1981;1:707-711.

13. Lucey MR, Brown KA, Everson GT, Fung JJ, Gish R, Keefe EB, et al. Minimal criteria for placement of adults on the liver transplant waiting list: a report of a national conference organized by the American Society of Transplant Physicians and the American Association for the Study of Liver Diseases. Transplantation 1998;66:956-962.

14. Burra P, Lucey MR. Liver transplantation in alcoholic patients. Transpl Int 2005;18:491-498.

15. Vaillant GE. The natural history of alcoholism and its relationship to liver transplantation. Liver Transpl Surg 1997;3:304310.

16. Egawa H, Nishimura K, Teramukai S, Yamamoto M, Umeshita $\mathrm{K}$, Furukawa $\mathrm{H}$, et al. Risk factors for alcohol relapse after liver transplantation for alcoholic cirrhosis in Japan. Liver Transpl 2014;20:298-310.

17. Lucey MR, Carr K, Beresford TP, Fisher LR, Shieck V, Brown $K A$, et al. Alcohol use after liver transplantation in alcoholics: a clinical cohort follow-up study. Hepatology 1997;25:12231227.

18. Gish RG, Lee A, Brooks L, Leung J, Lau JY, Moore DH 2nd. Long-term follow-up of patients diagnosed with alcohol dependence or alcohol abuse who were evaluated for liver transplantation. Liver Transpl 2001;7:581-587.

19. Bellamy CO, DiMartini AM, Ruppert K, Jain A, Dodson F, Torbenson $\mathrm{M}$, et al. Liver transplantation for alcoholic cirrhosis: long term follow-up and impact of disease recurrence. Transplantation 2001;72:619-626.

20. Tang H, Boulton R, Gunson B, Hubscher S, Neuberger J. Patterns of alcohol consumption after liver transplantation. Gut 1998;43:140-145.

21. Hartl J, Scherer MN, Loss M, Schnitzbauer A, Farkas S, Baier L, et al. Strong predictors for alcohol recidivism after liver transplantation: non-acceptance of the alcohol problem and abstinence of $<3$ months. Scand J Gastroenterol 2011;46:12571266.

22. De Gottardi A, Spahr L, Gelez P, Morard I, Mentha G, Guillaud O, et al. A simple score for predicting alcohol relapse after liver transplantation: results from 387 patients over 15 years. Arch Intern Med 2007;167:1183-1188.

23. Osorio RW, Ascher NL, Avery M, Bacchetti P, Roberts JP, Lake JR. Predicting recidivism after orthotopic liver transplantation for alcoholic liver disease. Hepatology 1994;20(1 Pt 1):105110.

24. Pageaux GP, Michel J, Coste V, Perney P, Possoz P, Perrigault $\mathrm{PF}$, et al. Alcoholic cirrhosis is a good indication for liver transplantation, even for cases of recidivism. Gut 1999;45:421426. 